\title{
LANSIA "SUCCESSFUL AGING; (UPAYA MEWUJUDKAN LANSIA YANG SEHAT SECARA FISIK, PSIKIS, SOSIAL DAN FINANSIAL)
}

\author{
Veni Fatmawati \\ veni_fatma@yahoo.co.id \\ Prodi S1 Fisioterapi Universitas Asyiyah Yogyakarta \\ Annisa Warastri \\ annisawarastri101@gmail.com \\ Prodi S1 Psikologi Universitas Asyiyah Yogyakarta \\ Agil Dhiemitra Aulia Dewi \\ agildhiemitra@unisayogya.ac.id \\ Prodi S1 Gizi Universitas Asyiyah Yogyakarta
}

\begin{abstract}
ABSTRAK
Tujuan dari program PKM ini adalah untuk membantu lansia guna mencapai successful aging yang diinginkan menjadi lansia yang sehat secara fisik, psikis, sosial dan finansialnya sehingga lansia bisa menikmati sisa-sisa kehidupannya dengan penuh kebahagiaan tanpa tekanan. Adapun metode yang akan diberikan adalah: (a) Membuat paguyuban lansia "successful aging”, (b) Merancang kegiatan-kegiatan yang dapat memenuhi kebutuhan fisik, kebutuhan psikologis, kebutuhan sosial dan kebutuhan finansial lansia. Berdasarkan Hasil evaluasi terhadap kegiatan PKM yang sudah berjalan, dapat diketahui bahwa ada perubahan pada diri lansia yang ada di kedua mitra. Perubahan tersebut dapat terlihat dari pola hidup sehat yang sudah berhasil lansia tunjukkan. Mulai dari: 1) Menu makan sudah disesuaikan dengan kondisi kesehatan lansia, 2) Membiasakan cuci tangan setelah beraktifitas, 3) Rutin mengikuti kegiatan PKM (cek kesehatan, jalan sehat, senam dan lain sebagainya).
\end{abstract}

Kata kunci; Successful Aging, Sehat, Fisik, Psikis, Sosial, Finansial.

\section{PENDAHULUAN}

Menjadi tua adalah sebuah kepastian yang pasti akan dialami oleh setiap orang. Menjadi tua berarti harus siap dengan segala koensekuensinya, mulai dari penurunan kemampuan gerak dan fungsi dan juga kemunduran dalam aspek-aspek yang lain. Kemunduran-kemunduran tersebut tentu akan berpengaruh terhadap kondisi kesehatan lansia. Sebagaimana yang dikemukakan oleh Mardiana, Yanih dan Zelfino (2014) mengatakan bahwa umur mempengaruhi terjadinya hipertensi. Dengan bertambahnya umur, resiko terkena hipertensi menjadi lebih besar. 
Pada usia lanjut. Hipertensi lebih sering ditemukan hanya berupa tekanan sistolik. Mardiana, Yanih dan Zelfino (2014) menegaskan bahwa tingginya hipertensi sejalan dengan bertambahnya umur, disebabkan oleh perubahan struktur pada pembuluh darah besar, terutama menyebabkan peningkatan tekanan darah sistolik biasanya setelah usia $\geq 60$ tahun.

Ketakutan serta gambaran akan keadaan yang semakin parah ditambah dengan menurunnya fungsi yang terdapat dalam tubuh memicu timbulnya pemikiran-pemikiran yang semakin berujung pada keadaan stres. (Maria, 2013). Wilkinson (2002) menyebutkan bahwa stres disebabkan oleh hal apapun yang membuat anda tegang, marah, frustasi, atau tidak bahagia. Stres pada seseorang bisa menjadi kesenangan bagi orang lain. Terlalu banyak stres akan mempengaruhi kesehatan dan kesejahteraan lansia

Menurut Hidayah (2013) stres yang terjadi pada lansia akan menjadi salah satu faktor terjadinya penyakit pada lansia dan begitu pula sebaliknya. Artinya, dengan adanya penurunan kemampuan fisik lansia dapat menyebabkan lansia menjadi stress, yang dulunya semua pekerjaan bisa dilakukan sendirian, kini terkadang harus dibantu orang lain. Perasaan membebani orang lain inilah yang dapat menyebabkan stress. Selain itu, stres yang dialami lansia juga akan melahirkan penyakit-penyakit lain pada lansia tersebut yang biasa dikenal dengan istilah psikosomatis.

Secara sederhana bisa disimpulkan bahwa penurunan kemampuan lansia akan akan membuat lansia stres dan stres tersebut akan semakin memperburuk kesehatan lansia. Kondisi ini bukanlah kondisi yang biasa-biasa saja, kondisi seperti ini harus dipahami sebagai informasi yang penting sehingga lansia yang ada disekitar kita bisa hidup bahagia dan dapat terbebas dari stress serta bisa menjadi lansia yang berhasil (successful aging).

Menurut Suardiman (2011) successful aging adalah suatu kondisi dimana seorang lansia tidak hanya berumur panjang tetapi juga umur panjang dalam kondisi sehat, sehingga memungkinkan untuk melakukan kegiatan secara mandiri, tetap berguna dan memberikan manfaat bagi keluarga dan kehidupan sosial. Kondisi demikian sering disebut sebagai harapan hidup untuk tetap aktif. 
Sebaliknya orang tidak menghendaki umur panjang, apabila umur panjang ini dilalui dalam keadaan sakit. Sedangkan Havigurst (dalam Ouwehand, et al 2007) mendefinisikan "successful aging" sebagai seseorang yang memiliki perasaan kebahagiaan dan kepuasaan hidup baik pada masa sekarang maupun masa lalu."

Successful aging seperti inilah sebenarnya yang diharapkan oleh semua lansia. Namun successful aging ini terkadang hanyalah sebuah harapan yang sulit untuk direalisasikan. Sebagai salah satu contoh, lansia yang ada di Dusun Pringgading dan Dusun Bungsing Desa Guwosari Pajangan Bantul yang juga mendambakan successful aging ini namun tidak kunjung bisa didapatkan. Sebagai informasi, Dusun Pringgading adalah sebuah dusun yang terletak di wilayah Desa Guwosari Kecamatan Pajangan Kabupaten Bantul. Dusun Pringgading sendiri terbagi kedalam dua wilayah yaitu Pringgading Utara dan Pringgading Selatan. Pringgading utara yang terdiri dari tiga RT yaitu RT 01 yang penduduknya berjumlah $41 \mathrm{KK}$, RT 02 berjumlah $37 \mathrm{KK}$, dan RT 06 berjumlah 21 KK. Adapun Pringgading selatan terdiri dari lima RT, yaitu RT 03 yang jumlah penduduknya $36 \mathrm{KK}$, RT 04 berjumlah $48 \mathrm{KK}$, RT 05 berjumlah $15 \mathrm{KK}$, RT 07 dan RT 08. Adapun dusun Bungsing, Dusun ini persis berada di sebelah timur Dusun Pringgading dengan jumlah pendudukan lebih kurang 586 jiwa yang terbagi kedalam empat rukun tetangga (rt). 100\% warga Dusun Bungsing adalah warga asli Desa Guwosari, tidak ada perumahan yang berada diwilayah dusun tersebut. Berbeda halnya dengan dusun pringgading yang 75\% warganya adalah warga perumahan yang tinggal di perumnas Guwosari dengan mata pencarian sebagian besar sebagai petani dan buruh pabrik.

Solusi yang ditawarkan bagi permasalahan yang dijumpai pada kedua mitra untuk mewujudkan lansia successful aging: Sehat Fisik, Psikis, Sosial dan Finansial adalah dengan cara: 1) Mendirikan paguyuban khusus bagi lansia, Paguyuban "Lansia Successful Anging", 2) Merancang kegiatan-kegiatan yang dapat memenuhi kebutuhan fisik lansia, 3) Merancang kegiatan-kegiatan yang dapat memenuhi kebutuhan psikologis lansia, 4) Merancang kegiatan-kegiatan yang dapat memenuhi kebutuhan Sosial lansia, 5) Merancang kegiatan-kegiatan yang dapat memenuhi kebutuhan Finansial lansia.

Fakultas Psikologi, Universitas Muhammadiyah Jember | 42 


\section{METODE PELAKSANAAN}

Ada beberapa cara yang Tim lakukan untuk membantu mitra dalam mewujudkan "Lansia Sukses (successful aging; sehat fisik, psikis, sosial dan finansial)". Beberapa cara tersebut adalah:

\section{1) Mendirikan Paguyuban Lansia}

Pendirian paguyuban lansia dalam kegiatan PKM ini cukup membantu dalam pelaksanaan kegiatan ini,. Karena kegiatan-kegiatan yang berhubungan dengan lansia akan lebih mudah dikoordinasikan dan dilakukan. Pendirian paguyuban lansia ini berada dibawah padukuhan Pringgading dan Dusun Bungsing.

\section{2) Merancang Kegiatan-Kegiatan Yang Dapat Memenuhi Kebutuhan Fisik}

\section{Lansia}

Ada beberapa kegiatan yang Tim lakukan untuk membantu memenuhi kebutuhan fisik lansia yang ada pada Mitra 1 dan Mitra 2, Seperti:

(a) Senam dan Jalan sehat lansia

Senam dan jalan sehat lansia ini dilakukan pada minggu ke empat. Senam dan jalan sehat lansia ini dilakukan secara bersama-sama, artinya tiga paguyuban lansia yang tersebar diwilayah Dusun Pringgading dan Dusun Bungsing ini dikumpulkan menjadi 1 dan dilakukan secara bergilir. Senam dan jalan sehat lansia dilakukan dengan tujuan: Semakin mempererat hubungan silaturahmi dan komunikasi antar lansia, Efisien dari segi waktu dan pembiayaan.

(b) Pemeriksaan Kesehatan

Pemeriksaan kesehatan yang meliputi; cek tekanan darah lansia, mengukur kadar gula darah, kolestrol, asam urat lansia, dan mengukur berat badan lansia ini akan dilakukan setiap 1 bulan sekali dan dilakukan oleh mahasiswa-mahasiswa prgogam studi S1 Fisioterapi Universitas 'Asyiyah Yogyakarta. 
(c) Menyediakan makanan sehat bagi lansia.

Menu makanan sehat ini disusun oleh Tim Pengabdi dari Prodi Fisioterapi dan juga prodi Psikologi serta dibantu oleh rekan-rekan Tim Pengabdi dari Program Studi S1 Gizi Universitas ‘Asyiyah Yogyakarta.

(d) Konsultasi kesehatan.

Konsultasi kesehatan lansia ini khususnya yang terkait dengan permasalahan-prmasalahan fisik lansia sepenuhnya ditangani oleh Dosen dan Mahasiswa Program Studi Fisioterapi sedangkan untuk permasalahan kesehatan lansia yang lain tim akan menghadirkan Dokter dalam setiap kegiatan konseling kesehatan pada lansia tersebut.

\section{3) Merancang Kegiatan-Kegiatan Yang Dapat Memenuhi Kebutuhan Psikologis Lansia}

Selain permasalahan kemunduran fungsi fisik, permasalahan lain yang lazim dialami oleh lansia adalah permasalahan-permasalahan yang berhubungan dengan kondisi psikologis lansia. Untuk itu, Tim memberikan beberapa kegiatan yang bisa menunjang kebutuhan psikologis lansia yang mungkin selama ini terabaikan. Seperti : Merancang kegiatan konseling lansia.

Kegiatan konseling atau layanan konseling psikologis lansia ini dilakukan secara bersamaan dengan layanan konsultasi kesehatan lansia. Konsultasi kesehatan dikoordinir oleh Tim dari Fisioterapi sedangkan layanan konsultasi psikologis akan dikoordinir oleh Tim dari prodi Psikologi.

4) Merancang kegiatan-kegiatan yang dapat memenuhi kebutuhan Sosial lansia

Kebutuhan sosial ini sebenarnya sudah dapat terpenuhi dalam kegiatankegiatan diatas, seperti: senam dan jalan sehat lansia, konsultasi medis, konsultasi psikologis dan lain sebagainya. Namun secara khusus, berkaitan dengan kebutuhan sosial ini pada lansia ini, Tim PKM akan memberikan kegiatan yang bisa menunjang kebutuhan sosial lansia. Kegiatan tersebut adalah bakti sosial khusus lansia. Dalam kegiatan bakti sosial ini, semua hal yang dibutuhkan dalam kegiatan baksos akan disediakan oleh Tim. Namun lansialah yang akan memberikan bingkisan baksos tersebut kepada lansia-lansia lain yang ada di panti- 
panti sosial. Hal ini bertujuan untuk menumbuhkan harga diri pada lansia. Hal ini disebabkan karena lansia selama ini merasa sebagai sosok yang lemah, sosok yang selalu menjadi pihak penerima dan tergantung kepada orang lain. Dengan adanya kegiatan bakti sosial ini diharapkan muncul konsep diri positif dalam diri lansia.

5) Merancang kegiatan-kegiatan yang dapat memenuhi kebutuhan Finansial lansia

Kondisi finansial lansia sudah bisa dipastikan mengalami perubahan dibandingkan dengan kondisi sebelum menjadi lansia. Sehingga adanya perubahan kondisi finansial ini sering kali menjadi salah satu penyebab stres pada lansia. Oleh sebab itu, tim PKM memberikan solusi yang sederhana terkait dengan kondisi finansial ini, yaitu dengan mengajak lansia untuk berkebun, menanam jenis-jenis sayuran yang dibutuhkan lansia dihalaman sekitar rumah mereka.

\section{HASIL DAN PEMBAHASAN}

Agar lansia yang ada di Dusun Pringgading dan Dusun Bungsing bisa menjadi "Lansia Sukses (successful aging; sehat fisik, psikis, sosial dan finansial)“ dapat dilakukan dengan memberikan kegiatan-kegiatan yang dapat memenuhi kebutuhan fisik, psikologis, sosial dan finansial lansia. Universitas 'Asyiyah Yogyakarta memiliki Program Studi S1 Fisioterapi yang salah satu bidang keterampilannya adalah Geriatri. Dosen dan Mahasiswa dari Program studi S1 Fisioterapi inilah nanti yang akan membantu memberikan pelatihan Senam bagi lansia dan mengkoordinir Jalan sehat lansia dan melakukan pemeriksaan dasar yang meliputi cek tensi, gula darah, dan asam urat.

Selain memiliki jurusan Fisioterapi, Universitas ‘Asyiyah Yogyakarta juga memiliki jurusan S1 Gizi. Dosen dan mahasiswa Jurusan S1 Gizi ini nantinya bertugas menyusun makanan sehat bagi lansia dan membantu menyediakan jenisjenis bibit tanaman dan sayuran yang bermanfaat untuk lansia. Sedangkan untuk memenuhi kebutuhan psikologis dan sosial lansia sepenuhnya akan dibantu pengembangannya oleh Dosen dan mahasiswa Program Studi Psikologi Universitas ‘Asyiyah Yogyakarta.

Fakultas Psikologi, Universitas Muhammadiyah Jember | 45 
Manfaat yang dirasakan adalah lansia bisa mengetahui kondisi kesehatan dan membantu mengatasi permasalah psikologisnya. Sedangkan manfaat untuk mahasiswa adalah mahasiswa bisa mempraktekkan ilmunya secara langsung kepada masyarakat dan kegiatan ini sekaligus sebagai lahan pengabdian buat dosen S1 Fisioterapi, S1 Gizi dan S1 Psikologi Universitas 'Asyiyah Yogyakarta.

Kegiatan PKM ini diawali dengan merancang kegiatan-kegiatan yang dapat memenuhi kebutuhan fisik, psikis, sosial dan finansial lansia. Agar kebutuhan fisik lansia dapat terpenuhi, Tim mengajak para lansia untuk senam, jalan sehat dan melakukan pemeriksaan kesehatan lansia. Selain itu, lansia yang ada pada kedua mitra diberikan kesempatan untuk mengkonsultasikan kondisi kesehatan mereka kepada Tim yang ada baik dari fisioterapis, ahli gizi dan juga psikolog.

Setelah serangkaian kegiatan PKM lansia successful aging ini dilakukan. Tim melakukan reseach sederhana untuk melihat capaian yang bisa didapatkan oleh para lansia. Adapun hasil yang dapat diperoleh dari adanya kegiatan PKM ini adalah adanya perubahan pola hidup sehat pada lansia yang ada di kedua mitra. Hal ini dapat dilihat dari gambar dibawah ini:

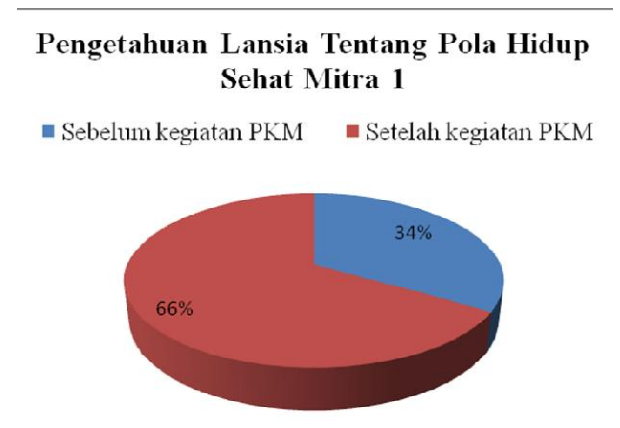

\section{Tingkat Pengetahuan Lansia Tentang Pola Hidup Sehat mitra 2}

- Sebelum kegiatan PKM $\square$ Setelah kegiatan PKM

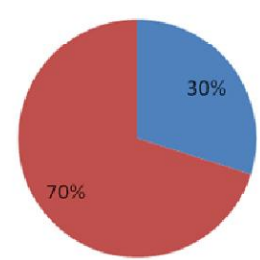

Gambar 1. Tingkat pengetahuan lansia tentang pola hidup sehat

Data diatas menunjukkan bahwa telah terjadi perubahan yang signifikan tentang tingkat pengetahuan lansia tentang pola hidup sehat. Perubahanperubahan tersebut dapat dilihat dari pola hidup sehat yang lansia tunjukkan. Seperti; 


\section{a. Menu makan sudah disesuaikan dengan kondisi kesehatan lansia,}

Sebelum adanya kegiatan PKM ini, lansia yang ada dikedua mitra cenderung mengkonsumsi jenis makanan apapun tampa melihat kondisi kesehatan mereka. Hal ini tentunya sangat beresiko, mengingat lansia sudah mengalami banyak penurunan kekuatan dan daya tahan tubuhnya. Namun setelah para lansia ini secara aktif mengikuti kegiatan PKM lansia successful aging, mereka mulai memilih jenis-jenis makanan yang tentunya cocok dan sesuai dengan kondisi kesehatan mereka.

\section{b. Membiasakan cuci tangan setelah beraktifitas}

Kebiasaan baik lain yang mulai ditunjukkan oleh lansia adalah mulai munculnya kebiasaan baik untuk mencuci anggota tubuh setelah beraktifitas. Perilaku seperti ini sebelumnya jarang dilakukan oleh lansia dan warga yang ada dikedua mitra. Karena warga yang ada di kedua mitra ini adalah warga yang tinggal di pelosok desa yang tidak terbiasa dengan pola hidup sehat.

\section{c. Rutin mengikuti kegiatan PKM (cek kesehatan, jalan sehat, senam dan lain sebagainya)}

Bentuk keberhasilan lain dari kegiatan PKM ini adalah tumbuhnya semangat dan motivasi pada diri lansia untuk mengikuti pola hidup sehat. Mulai dari aktif secara rutin mengikuti cek kesehatan dan kegiatan-kegiatan lain yang Tim PKM lakukan.

Meningkatnya pemahaman lansia tentang pola hidup sehat ini diharapkan dapat menumbuhkan rasa optimisme lansia dalam memandang kehidupan ini. Sehingga kesehatan fisik lansia, kesehatan psikis lansia, kebutuhan sosial dan bahkan finansial mereka dapat terpenuhi dengan baik.

\section{KESIMPULAN DAN SARAN}

\section{Kesimpulan}

Mengacu kepada uraian-uraian kegiatan PKM yang sudah berjalan diatas, maka dapat diketahui bahwa sudah ada perubahan yang berarti pada diri lansia yang ada di kedua mitra. Perubahan tersebut dapat terlihat dari pola hidup sehat yang sudah berhasil lansia tunjukkan. Mulai dari: 1) Menu makan sudah 
disesuaikan dengan kondisi kesehatan lansia, 2) Membiasakan cuci tangan setelah beraktifitas, 3) Rutin mengikuti kegiatan PKM (cek kesehatan, jalan sehat, senam dan lain sebagainya).

\section{Saran}

Berdasarkan hasil-hasil temuan diatas, maka Tim pengabdian successful aging memberikan beberapa saran berikut ini:

1. Pemerintah Desa Bungsing dan Pringgading.

Berdasarkan temuan diatas, maka diharapkan pemerintah desa bisa memfasilitasi kebutuhan hidup sehat warga yang ada di wilayah pemerintahannya. Seperti menyediakan fasilitas-fasilitas yang menunjang kesehatan warga khususnya lansia.

2. Warga Bungsing dan Pringgading

Kepada warga masyarakat yang ada di Dusun Bungsing dan Pringgading agar memperhatikan pola hidup sehatnya. Menjaga kesehatan fisik, memperhatikan menu makanan (gizi) dan menjaga kebersihan lingkungan sekitar. Dengan melakukan itusemua diharapkan kebutuhan lansia untuk successful aging bisa segera terpenuhi.

\section{DAFTAR PUSTAKA}

Hidayah, Nur (2013) Stress Pada Lansia Menjadi Faktor Penyebab Dan Akibat Terjadinya Penyakit. http://journal.unusa.ac.id/index.php/jhs/article/view/21

Mardiana, Yanih dan Zelfino (2014) hubungan antara tingkat stres lansia dan kejadian hipertensi pada lansia di rw 01 kunciran tangerang. Forum Ilmiah, Volume 11 Nomor 2, Mei 2014

Maria, Margaretha Shinta Pratiwi (2013) Stress pada lansia. PSYCHO IDEA, Tahun 11 No.1, Februari 2013 